\title{
A Measure of the Impact of Tenure
}

\section{Richard W. Meyer}

\begin{abstract}
Although prevalent on campuses, the rationale for tenure lacks an economic explanation of its influence on campus outcomes such as teaching. Because only half of American academic librarians are eligible for tenure, they comprise a sample appropriate for testing the qualitative impact of tenure. The model reported here shows that the quality of institutions is at least partially predictable by the number of librarians and their tenure status. Tenure, therefore, appears to have an impact as a monitor of quality in academe.
\end{abstract}

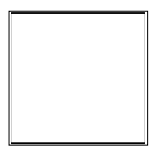

inancial contingencies, the agenda of governing boards, state government activity, court rulings, and the revoca-

tion of mandatory retirement all pose threats to the continuance of tenure that have recently renewed concern among academics. ${ }^{1}$ In response to these threats, faculty tend to reply with rhetorical arguments defending tenure on the basis of academic freedom or related issues. Most of those arguments imply the premise that tenure adds value to campuses. This paper offers a test of the impact of tenure on colleges.

A determination of the impact of tenure on the quality of institutions requires a test comparing institutions that apply tenure with those that do not. Because nearly all four-year institutions award tenure to their teaching faculty, a test with that cohort is impossible. Librarians, on the other hand, are eligible for tenure at fewer than half the four-year institutions in America. ${ }^{2}$ Some of these institutions provide librarians with faculty status, which includes tenure review by one's peers, and some do not. This specialized group of faculty offers a valuable oppor- tunity for measuring the impact of tenure on the success of colleges and thus for systematically comparing colleges for quality.

In both liberal arts teaching and research university settings, the campus administration requires faculty involvement in teaching and scholarship. An earlier analysis reported the impact or the effects of faculty status for librarians on research universities. ${ }^{3}$ Research appears to receive less emphasis in colleges, perhaps because of less demand by the outside community for the associated output products. Colleges may depend on scholarship more for developmental support of highquality instruction; therefore, the impact of tenure may be different in this setting. Some colleges confer faculty status on librarians, requiring them to participate in scholarship and awarding them tenure. This paper opens with a brief property rights explanation of tenure and discusses variations in the effects of faculty status for librarians. It then reports on empirical work measuring the impact of tenure for librarians on institutional success and concludes with comments on its qualitative effects. 


\section{The Nature of Tenure and Its Effects for Librarians}

At the outset, understanding how the institutionalization of tenure serves as a monitor of quality helps to explain why higher education tends to require both teaching and scholarship of the faculty. Probably most university governing boards maintain some kind of agenda to continually improve the quality of their institutions. Because university success derives in large measure from the quality of its faculty, ensuring retention of the best possible faculty requires a process to monitor quality. Tenure review, which is ubiquitous in academe, provides the process to implement the board's agenda and to assess the quality of the institution's faculty. That is, only those faculty members with the superior intellectual skills needed to be effective in both scholarship and teaching should survive the process of being awarded tenure.

Teaching and learning are two facets of the same enterprise. To do either one well, one has to do both.

In the absence of government mandate, institutional forms that evolve tend to do so because they are efficient. Across academic institutions, the performance of faculty generally is evaluated with procedures that are consistent from place to place and that focus on scholarship, teaching, and service contributions. The peer review process may be focused at the department, college, or overall institution level, but scholarship and teaching tend to be the two areas where evaluation effort is concentrated. Of course, service also may be considered in evaluations but often is not given as much importance because it frequently is rewarded directly. Consulting payments and royalties accrue to work offered outside the university, and therefore service is inappropriate to consider heavily in promotion and tenure reviews lest it be doubly rewarded. Institutions appear to press faculty to superior performance in service and instruc- tion, but to reward them on the basis of scholarship. This may be as it should be because of operational efficiency in promoting quality.

An argument can be made that the synergy between scholarship and teaching demands participation in both. Teaching and learning are two facets of the same enterprise. To do either one well, one has to do both. Presumably, the risk imposed by outside review of scholarly submissions to journals dictates the requirement that the scholar be conversant with the relevant work in the field. That familiarity enhances knowledge imparted in the classroom. Conversely, classroom interaction and curiosity over motivations, point of view, and activity of other scholars as reported in their work presumably induces interest in further scholarly examination. These two activities reinforce each other synergistically, but scholarship appears to be the driving element. It may be possible to do research well without being involved in teaching, but one cannot teach what one does not know, and scholarship enhances knowledge. Furthermore, scholarship lends itself to evaluation more readily than teaching does.

Research output is rather easily measured. Some disciplines even have ranked the overall quality of scholarly publications in their discipline. The measure of the quality of one's work thus can be quantitatively compared with that of one's peers. An important aspect of measuring scholarship is that peers outside the local institution contribute directly to monitoring quality by reviewing scholarly submissions for publication. This means that the quality of faculty in a given institution is measured against a nationwide cohort. On the other hand, teaching is neither prone to objective, quantitative measures nor significantly subject to outside review. Therefore, some other activity to promote teaching quality often appears to be substituted for the low-cost evaluation measure applied to scholarship. The most common substitutes that have emerged are oral encouragement, 
rhetoric, and evaluation by students. Continual reminders to the faculty of the primacy of teaching may encourage quality to some extent. Rhetoric works to that same effect through campus publicity (e.g., quality statements in campus bulletins and so forth). Student evaluations impose some risk of failure on faculty, which then disciplines their work. If the effort to both evaluate scholarship and encourage good teaching does not take place, one endeavor might suffer decline to the detriment of both. However, careful monitoring of scholarship is sufficient to guarantee quality in both areas because the energy expended for scholarship accrues benefits in the classroom. The tenure review process monitors the synergy resulting from this combination.

Historically, tenure review has been a positive vector of quality. In the United States in general, the decision to award tenure was, until the early 1900s, typically made with the presumption of permanence by the president of the university at the time faculty were hired. Dismissals do not appear to have decreased with the adoption of tenure. ${ }^{4}$ Although tenure is usually defended on the basis that it protects academic freedom, little change appears in the rate of overall dismissal from colleges or universities when failure to achieve tenure is included in the dismissal statistics subsequent to the institutionalization of peer review. Yet it was faculty, not administrators, who insisted on its implementation. What purpose then does the tenure review process serve? It must serve some purpose; otherwise, in the absence of a government mandate, it would not be ubiquitous. Research reported elsewhere suggests that the evaluation of faculty for tenure is a quality-enhancing mechanism..$^{5}$ Faculty participation in the hiring, promotion, and tenure process is preferred to having these decisions made only by administrators.

The rationale for tenure rests on the recognition that the faculty members of the department are the beneficiaries of its reputation for quality. That is, the quality that accrues to the department (or college or institution) through the hiring of superior scholars can be traded to some extent by its individual members for remuneration outside the institution. Faculty recognize, perhaps intuitively, that the reputation of high-quality departments makes it easier to secure better-paying jobs at other institutions, as well as to enhance their incomes through consulting, speaking honoraria, and so forth. Ergo, there is an incentive in place for departments to collectively recruit and promote faculty of ever-higher quality. Delegation of authority to award tenure to the faculty provides the necessary mechanism to control hiring and thus to elevate quality. Whether this mechanism and its results are the same for librarians was the focus of the earlier research as well as the research reported here. Presumably, what works for teaching faculty also works for librarians. If tenure improves the quality of teaching faculty, it also will improve the quality of librarians with a resulting positive impact on institutional success and quality.

In this context, faculty status for librarians is only meaningful where tenure is implemented for librarians and the retention decision is delegated. That is, institutions can be differentiated as to whether faculty status for librarians is truly available on the basis of tenure availability. The synergy between librarianship and scholarship will not work when both are not required or where the monitoring process of tenure review is not present and essentially delegated to the department. For the purposes of this paper, faculty status for librarians is defined as present only in those institutions where librarians are called faculty, where they possess most of the perquisites of faculty, and where they have tenure. This definition is consistent with ALA standards. ${ }^{6}$

Within this framework, the effects of faculty status in the research-oriented setting have been reported elsewhere. ${ }^{7}$ Briefly, that analysis showed that the effects of faculty status in research institutions are twofold. First, the study sug- 
gested that faculty status for librarians provides a means to leverage the salaries of librarians upward. This earlier study looked at two data sets, comparing salaries of librarians across one campus with teaching faculty and across fifteen libraries with each other. The comparisons were made by means of ordinary least squares regression of individual salaries against several variables. Faculty status appears to work effectively as a substitute for collective bargaining and to achieve approximately the same results. Institutions where librarians have faculty status pay salaries to librarians that are about six percent higher than those paid by institutions where librarians do not have faculty status. This alone suffices to explain the pressure exerted by librarians to achieve faculty status.

Second, the study also reported that the diversion of energy required to implement faculty status imposes a cost on the overall research productivity of campuses. ${ }^{8}$ Research-oriented institutions that include librarians in the faculty produce approximately nine percent less research. This latter result emerged from a model that regressed research productivity in the form of Ph.D. degrees awarded against several variables, including the presence of faculty status. The analysis was limited to the group of institutions represented in the Association of Research Libraries-institutions that place a heavy emphasis on research. These results tend to explain the reluctance of some campuses to implement faculty status but do not explain its presence on many campuses. Therefore, the effects of faculty status described by the previous analysis should not be extended to colleges that emphasize teaching. Determining the effects of faculty status on the quality of such institutions requires further study. The rest of this paper reports on that work.

\section{The Effect of Tenure on Teaching Productivity}

Intuition suggests that tenure for librarians plays a positive role in the overall teaching quality of academic institutions. The defense of faculty status for librarians often includes the argument that librarians and teaching faculty are partners in the academic experience. For example, bibliographic instruction is an important aspect of library service. Usually, bibliographic instruction involves at least minimal cooperation between instructor and librarian. It is intended that the joint effort of teaching faculty and librarians will promote information literacy and bibliographic skills among students. Of all the outcomes expected of graduates of higher education, the ability to acquire, evaluate, and use information-particularly for literary expression - is highly regarded and fundamental to the success of the institution. This requires that institutional pedagogy incorporate a library element. A productive, peer-level working relationship between teachers and librarians presumably produces a stronger synergy. If librarians are recognized as faculty, the working relationship starts as a partnership.

Testing the validity of what intuition leads one to believe benefits from empirical analysis. ${ }^{9}$ The tests reported here focus on the effects of tenure for librarians on the teaching quality of colleges. The data set chosen for this analysis came from a broad group of private liberal arts teaching institutions informally organized as the Oberlin Group. These schools are all highly selective of students and place an emphasis on a high-quality liberal arts education. They may tend to emphasize teaching, even though they usually require scholarship of the faculty as well. If the intuition is correct, tenure for librarians should contribute to the quality of institutions as measured by a teaching/learning metric. A widely accepted measure of teaching effectiveness would provide for a reliable test.

Numerous studies on various aspects of the impact of college on students have been summarized elsewhere by social scientists. ${ }^{10}$ College impacts students on a number of fronts including socioeconomic outcomes, attitudes and values, psychosocial change, moral development, 


\begin{tabular}{|c|c|c|}
\hline \multicolumn{3}{|c|}{$\begin{array}{c}\text { TABLE } 1 \\
\text { Variables Used in the Model to Predict Success among } \\
\text { Oberlin Group Institutions }\end{array}$} \\
\hline $\begin{array}{l}\text { Dependent } \\
\text { Variables }\end{array}$ & & Mean \\
\hline GRADRATE & Percentage of students who graduate within five years & 78.00 \\
\hline GRADATTND & $\begin{array}{l}\text { Percentage of alumni who matriculate in professional } \\
\text { or graduate schools }\end{array}$ & 31.75 \\
\hline AVESAT & $\begin{array}{l}\text { Average SAT scores for entering first year students of } \\
\text { individual colleges }\end{array}$ & 1,152 \\
\hline $\begin{array}{l}\text { Independent } \\
\text { Variables: }\end{array}$ & & Mean \\
\hline AVESAT & $\begin{array}{l}\text { Same as above; used here as a predictor of GRADRATE } \\
\text { and GRADATTND }\end{array}$ & 1,152 \\
\hline SAT\%HIGH & $\begin{array}{l}\text { Percentage of entering students with verbal SAT scores } \\
\text { greater than } 500\end{array}$ & 80.77 \\
\hline NETPRICE & All costs of enrolling minus financial aid & $\$ 12,694$ \\
\hline FACPHD & Percent of teaching faculty who possess a Ph.D. & 85.73 \\
\hline ENROLMNT & Total head count enrollment & 1,915 \\
\hline E\&GEXPND & Total educational budget & $\$ 34,000,000$ \\
\hline ENDWMNT & Total endowment of the institution & $\$ 118,000,000$ \\
\hline ALUMGIVE & Percent of alumni who provide financial support & 39.89 \\
\hline LIBRNS & Number of professional librarians employed & 9.99 \\
\hline TENURE & $\begin{array}{l}\text { Dummy variable: } 1=\text { tenure for librarians; } \\
0=\text { tenure is not available to librarians }\end{array}$ & 0.17 \\
\hline ILLRECD & $\begin{array}{l}\text { Number of interlibrary loans received annually } \\
\text { from other campuses }\end{array}$ & 3,487 \\
\hline
\end{tabular}

quality of life, intergenerational effects, in addition to learning and, presumably, cognitive development. The results of these studies suggest that learning and cognitive development may be the only outcomes that lend themselves to quantitative assessment. Therefore, the instructional success of colleges could be measured directly by the difference between GRE and SAT scores for graduating individuals. This would provide a reliable test of the variation in success achieved by institutions. Unfortunately for the study reported here, data could not be obtained on average GRE scores tied to the loci of undergraduate matriculation. Thus, some metric was needed to substitute for this measure.

A corollary of the research summarized elsewhere indicates that in actual practice, the choice of college does not impact significantly on the cognitive development and learning of individuals. The institution chosen by an individual appears to be nearly irrelevant in this area because the variables that tend to drive cognitive development are internal to the individual ${ }^{11}$ This corollary yields two results. First, it suggests that the success of institutions depends on their effectiveness in affecting the other outcomes associated with going to college. Otherwise, the potential student is left with little motivation to choose anything other than the cheapest, closest school. Second, it makes it possible to use SAT scores as a proxy for the overall success of colleges because the difference between GRE and SAT scores does not tend to vary with choice 


\begin{tabular}{|c|c|c|c|c|c|c|}
\hline \multicolumn{7}{|c|}{$\begin{array}{c}\text { TABLE } 2 \\
\text { Determinants of Success for Oberlin Group Institutions Based on Graduation } \\
\text { Rate, Rate of Graduate School Matriculation, and Average SAT Scores } \\
\end{array}$} \\
\hline \multirow[b]{2}{*}{ Independent } & \multicolumn{2}{|c|}{ GRADRATE } & \multicolumn{2}{|c|}{ Dependent Variable } & \multicolumn{2}{|c|}{ AVESAT } \\
\hline & Parameter & $\begin{array}{l}\text { t-statistic } \\
\text { estimate }\end{array}$ & Parameter & $\begin{array}{l}\text { t-statistic } \\
\text { estimate }\end{array}$ & Parameter & $\begin{array}{l}\text { t-statistic } \\
\text { estimate }\end{array}$ \\
\hline NETPRICE & 0.0002 & 0.95 & & & & \\
\hline SAT\%HIGH & 0.1268 & $1.52 \%$ & & & & \\
\hline E\&GEXPND & 0.00003 & $2.17 * *$ & & & 0.0004 & $2.76 * * *$ \\
\hline ENROLMNT & -0.0058 & $-2.40 * *$ & -0.0074 & $-3.70 * * *$ & -0.0729 & $-3.03 * * *$ \\
\hline ALUMGIVE & & & & & 2.9267 & $2.97 * * *$ \\
\hline ENDWMNT & & & 0.0000 & $1.70 *$ & & \\
\hline FACPHD & & & 0.6996 & $3.69 * * *$ & & \\
\hline AVESAT & & & -0.0440 & $-2.23 * *$ & & \\
\hline ILLRECD & & & 0.0011 & $1.53 \%$ & & \\
\hline LIBRNS & 0.6484 & $1.93 *$ & & & 6.3060 & $2.29 * *$ \\
\hline TENURE & 2.6731 & $1.02 \%$ & 12.0504 & $3.45 * * *$ & 26.5694 & 1.12 \\
\hline R Squared & 0.5494 & & 0.4057 & & 0.5595 & \\
\hline F Ratio & $7.72 * * *$ & & $4.44 * * *$ & & $11.18 * * *$ & \\
\hline No. Observations & 45 & & 46 & & 50 & \\
\hline $\begin{array}{l}* * \text { significant at the } 0 \\
* * \text { significant at the } 0 . \\
* \text { significant at the } 0.1 \\
+ \text { significant in a one } t\end{array}$ & $\begin{array}{l}0.01 \text { level } \\
05 \text { level } \\
0 \text { level } \\
\text { tailed test }\end{array}$ & & & & & \\
\hline
\end{tabular}

of college. ${ }^{12}$ In addition, another study has shown GRE scores to be reliably predicable from SAT scores. ${ }^{13}$

One government-sponsored study provided a comprehensive model with a reliable paradigm of independent variables suggesting appropriate dependent variables to proxy for cognitive development and learning. ${ }^{14}$ The study measured the success of colleges in terms of the quality of each institution related to its price. It identified SAT scores, reputation, and graduation rate as acceptable proxies to measure the success of campuses in furthering the development of students. In addition, the rate at which alumni acquire professional and Ph.D. degrees also will proxy for the success of undergraduate liberal arts institutions. This variable provides a particularly important test because the contribution of librarians may be concentrated on providing skills needed to succeed in graduate school. The dependent variables that yielded the most robust results are defined in table 1.
Independent variables identified as most meaningful in the governmentsponsored model are represented by those also defined in table $1 .{ }^{15}$ In addition to graduation rate, SAT averages and ranking scores from several popular evaluations were tried as the dependent variable. The percentage of students matriculating in professional and graduate programs also was used as a dependent variable. These quality measures were regressed against the independent variables listed in table 1, including the presence of faculty status for librarians as denoted by TENURE. Independent variables utilized in the model are described in table 1.

Data from sixty-seven members of the Oberlin Group of undergraduate liberal arts institutions were analyzed using ordinary least squares regression. Each of three quality measures-graduation rate (GRADRATE), graduate school attendance (GRADATTND), and average SAT scores (AVESAT) - provided useful mod- 
els. (Several variables provided by ratings services of the quality of programs were tried in the regression with insignificant results.) The results of the analyses appear in table 2. The most robust result is displayed for each model because there is some correlation between several of the variables listed. For example, educational and general expenditures (E\&GEXPND), endowment (ENDWMNT), and alumni donations (ALUMGIVE) proxy for each other. The strongest model containing each is displayed. TENURE is not highly correlated with the other variables; thus, concern is allayed that it may proxy for variables such as average SAT scores (AVESAT), which otherwise strongly predict the dependent variables.

With each of the quality measures used, the models hypothesize that the presence of tenure for librarians will statistically, significantly, and positively predict the dependent variable. The analysis allows us to evaluate the null hypothesis that faculty status for librarians will be an insignificant predictor of the independent variable. Comment on the variables and results is appropriate. Graduation rate (GRADRATE), percentage of alumni who attend graduate school (GRADATTND), and average SAT scores (AVESAT) were chosen as the independent variables on the basis of ready availability of data and the previously cited research which suggested them to be reasonable measures of academic or teaching quality.

The dependent variables were selected based on previous studies. The percentage of entering students with SAT verbal scores of 500 or better (SAT\%HIGH) and average SAT scores (AVESAT) presents measures of the average learning ability of the students at each school. Presumably, better students (e.g., higher SAT scores) will have a higher likelihood of graduating. The analyses reported elsewhere consistently found that this variable is a positive, statistically significant predictor of graduation rate. The analysis here corroborates those studies. In the case of the costs of attendance minus fi- nancial aid (NETPRICE), the government-sponsored study cited earlier showed distinctly that lower-cost, highquality institutions have greater success in graduating their students. Therefore, this variable was expected to be positive and significant. However, this expectation was not borne out in any of the models reported in table 2. NETPRICE is not a statistically significant predictor of success in graduating students in this study. The percent of teaching faculty who possess a Ph.D. (FACPHD) provides control for the level of education of faculty. In the government study, the additional variables of enrollment (ENROLMNT) and E\&G expenditures (E\&GEXPND) reliably helped predict success of colleges in graduating their students. Both variables were expected to be significant. ENROLMNT was expected to be negatively correlated with success, and E\&GEXPND was expected to be positively correlated. Lower enrollments provide students a more favorable environment, presumably due to lower transactions costs associated with social interactions and administrative monitoring of student problems. Conversely, higher expenditures as proxied by E\&GEXPND, ENDWMNT, and ALUMGIVE, through the opportunity they provide for more extensive services and higher-quality resources, should positively affect student success. In this study, all these variables held as consistent predictors in the direction previously determined.

Three additional variables were added to extend the studies done by others by taking into account the impact of librarians on campus quality. The TENURE variable indicates the presence of faculty status for librarians. If the central hypothesis is correct, TENURE should be significant and positive. Similarly, the variable for the number of librarians (LIBRNS) provided an additional related measure of quality based on the presumption that the more available librarians are, the likelier students are to succeed with instructional exercises involving bibliographic skills. This variable also should positively 
predict institutional success. The number of interlibrary loans received annually from other campuses (ILLRCD) provides a useful measure of the involvement of students in instructional exercises-exercises presumably integral to success in research and later in graduate school.

The results of the analysis are consistent with those of the other studies noted above. That is, the variables found to be reliable predictors in other studies also tend to be reliable in this study, thus corroborating the validity of the model used. Furthermore the variables tend to be consistent with intuition about what increases the likelihood that any given individual will succeed in graduating from college, or going to graduate school, or developing intellectually. A cohort of better students-a high number with average verbal SAT score over 500—will tend to increase graduation rates. As enrollment increases, the likelihood of graduating decreases. Smaller schools are more successful in getting their students through. As the amount expended on the educational and general budget is increased, the likelihood that students will graduate increases. Furthermore, to the extent that financial security increases with the percent of alumni who contribute money or with total endowment, the likelihood of success in graduate school and of greater cognitive development increases. That is, spend more money on help provided for students and they will do better. This is supported further by the positive impact of faculty with Ph.D. degrees on attendance in graduate school.

The outcome of the analysis showed that the number of librarians is a positive predictor of graduation rate and teaching success as measured by GRADRATE and AVESAT. The presence of faculty status for librarians (TENURE) is a weak positive predictor of graduation rate and cognitive development, where it was statistically significant in a one-tailed test in the first case and positive in sign, although not significant, in the second case. TENURE also is a powerful predictor of, and positively correlated with, graduate school attendance. Moreover, the number of interlibrary loans received (ILLRECD) is positively correlated with graduate school attendance and is significant in a one-tailed test.

In addition to extending the model with a variable to control for the number of librarians, all three versions of the model also contain the dummy variable, TENURE, to control for the presence of faculty status for librarians. As revealed by the number of librarians (LIBRNS), graduation rate increases for every librarian added to the faculty. So, too, the presence of librarians contributes positively to the overall intellectual development of students as measured by average SAT scores (AVESAT). This effect is gratifying to note and provides significant leverage to library directors making an argument for added positions. At the same time, the presence of faculty status (TENURE) has a positive sign related to graduation rate. Furthermore, it is a powerful, statistically significant predictor of attendance in graduate school. This particular result fits naturally with the expectation that librarians, especially good ones, would most positively impact graduate school success of alumni because of their influence on bibliographic skills. Therefore, it appears safe to assume that the percentage of students who graduate can be predicted partially on the basis of whether librarians have tenure. In other words, the number of librarians and the availability of tenure do seem to contribute to the quality of the teaching effort of undergraduate liberal arts institutions.

Because no direct measure of cognitive development is available, the results should not be taken as conclusive evidence that the number of librarians and faculty status contributes to the quality of the institution. However, the evidence shown here supports the contention that campuses with more librarians or with librarians with the personal quality to have survived tenure review are predictably more successful or have higher quality. Following that, if the individual quality of librarians can be elevated by the 
rigor of the tenure process, they will contribute even more to the overall quality of the campus and will have a particularly strong impact on the success of alumni in graduate school.

\section{Conclusion}

The background research summarized before examined the issue of faculty status for librarians and helped explain why some members of the library profession have sought this faculty status. Tenure for librarians seems to have been implemented, in part, because it leverages the salaries of librarians upward. In addition to being a low-cost alternative to collective bargaining in institutions where efforts to seek salary increases were warranted, faculty status also fulfills the need for an alternative productive outlet among librarians interested in scholarship and service. This impact is accompanied by a reduction in the research productivity of campuses where research is important. Apparently, the diversion of energy required for librarians to conduct personal research detracts measurably from their success in assisting campus research productivity.

The current investigation suggests that on campuses where teaching is important, the impact of faculty status appears to be significant. The analysis as extended in this study indicates that the number of librarians and whether they are eligible for tenure affects the quality of institutions as measured by graduation rate, graduate school attendance, and cognitive development. That is, faculty status including tenure for librarians has a positive impact on the success of institutions concentrating on teaching. This positive impact lends some credence to the intuitive assertion that high-quality librarianship improves the instructional quality of institutions. Some institutions have collectively decided to pay the price of tenure review to enhance the quality of librarianship, resulting in a financial reward to librarians and positive benefits to institutions that concentrate on teaching.
Explaining the beneficial impact of librarians on the quality of the academic institution requires little imagination. The success of students in finding material relevant to their assignments depends on the extent of their bibliographic skills. These skills are positively affected by the number of opportunities they have to receive bibliographic instruction, which is dependent on the number of librarians assigned to provide classroom bibliographic instruction and one-on-one tutorials at the reference desk. Similar to some instructors who teach better than others, some librarians have better instructional skills so that the quality of librarianship likely enhances skills development in students.

There are many other ways in which the quantity and quality of librarians can affect institutional quality positively. The bibliographic structure of online catalogs contains complexities that require professional time with authority control, error corrections, and bibliographic enhancements. Additional labor applied to automation systems or other technologies can reduce user frustration and shorten the time students need to identify research materials. Easier access leads to extended reading and improved writing. Furthermore, the availability of added labor results in improved collection development, more attention to detail, and better production control. All of these improve user success.

Although no statistical study ever provides incontrovertible proof of an assertion, this study certainly lends credible evidence to support rhetoric in defense of tenure. The model simply predicts that across a mix of institutions, those with tenure for librarians tend to be higher quality by the measures employed here. Each year, the number of teaching-oriented colleges that adopt tenure review for librarians increases. This appears to be in consort with the common wisdom shown by college governing boards, which almost unanimously monitor quality through tenure review, that tenure has value. 


\section{Notes}

1. For recent examples, see: "New Light on Tenure," Chronicle of Higher Education 41, no. 31 (Apr. 1995): A16-A22; Cary Nelson, Will Teach for Food: Academic Labor in Crisis (Minneapolis and London: Univ. of Minnesota Pr., 1997); Peter Schmidt, "Governors Want Fundamental Changes in Colleges, Question Place of Tenure," Chronicle of Higher Education 44, no. 41 (June 1998): A38; Robin Wilson, "Wesleyan U. Wins Suit Challenging a Tenure Denial," Chronicle of Higher Education 44, no. 48 (Aug. 1998): A12; Dennis Wrong, "The Challenge to Tenure," Dissent 45, no. 3 (summer 1998): 85-87.

2. For statistical normalization, the analysis reported on here was conducted on data from the early 1990s, when the number of colleges with tenure for librarians was almost half.

3. Richard W. Meyer, "Librarian Salaries: Paid What We're Worth?" College E Research Libraries News 51 (June 1990): 504-9.

4. Walter P. Metzger, "Academic Tenure in America: A Historical Essay," in Faculty Tenure: A Report and Recommendations by the Commission on Academic Tenure in Higher Education (San Francisco: Jossey-Bass, 1973), 93-159.

5. Robert E. McCormick and Roger E. Meiners, "University Governance: A Property Rights Perspective," Journal of Law and Economics 31 (Oct. 1988): 423-42.

6. Association of College and Research Libraries, "Standards for Faculty Status for College and University Librarians," College E Research Libraries News 53, no. 5 (May 1992): 317-18.

7. Richard W. Meyer, "Earnings Gains through the Institutionalized Standard of Faculty Status," Library Administration and Management, 4, no. 4 (fall 1990): 184-93.

8. Ibid.

9. The reader who is skeptical would be correct to observe that nothing can be proved with statistics. Similarly, a map of Missouri cannot be used to prove that St. Louis is located on the eastern border of the state at the confluence of two rivers. However, the map would be easily acceptable as a predictor of direction for a traveler destined for that city. In a related way, ordinary least squares regression analysis provides a powerful predictor of outcomes, helping us to understand what factors result in particular conditions.

10. Ernest T. Pascarella and Patrick T. Terenzini, How College Affects Students: Findings and Insights from Twenty Years of Research. (San Francisco: Jossey-Bass, 1991).

11. Ibid., 79-80.

12. Ibid., 103.

13. Linda L. Walsdorf, An Examination of the Relationship between Scholastic Aptitude and Graduate Records Examination Scores (Master's thesis, Trinity University, 1991).

14. Jeffrey L. Gilmore, Price and Quality in Higher Education. (Washington, D.C.: Office of Research, U.S. Department of Education, 1991).

15. Ibid. 